\title{
Perfil de ácidos graxos na carne de novilhos de diferentes idades e grupos genéticos terminados em confinamento
}

\section{Patrícia Alessandra Meneguzzi Metz ${ }^{1}$, Luís Fernando Glasenapp de Menezes², Angélica Pereira dos Santos ${ }^{3}$, Ivan Luiz Brondani ${ }^{4}$, João Restle ${ }^{5}$, Dante Pazzanese Duarte Lanna ${ }^{6}$}

${ }^{1}$ Mestranda do Programa de Pós-Graduação em Zootecnia, UFSM.

2 Doutorando do Programa de Pós-Graduação em Zootecnia, UFSM.

${ }^{3}$ Doutorando do Programa de Pós-Graduação em Zootecnia, UFRGS.

${ }^{4}$ Departamento de Zootecnia, UFSM.

5 Pesquisador visitante do CNPq no Departamento de Produção Animal da Universidade Federal de Goiás (UFG).

${ }^{6}$ Departamento de Zootecnia, ESALQ/USP.

RESUMO - Foram utilizados 24 bovinos machos castrados, pertencentes a quatro grupos genéticos ( $5 / 8$ Charolês $(\mathrm{CH})$ $3 / 8$ Nelore (NE); $5 / 8 \mathrm{NE}^{3} / 8 \mathrm{CH} ;{ }^{3 / 4} \mathrm{CH} 1 / 4 \mathrm{NE} \mathrm{e} 3 / 4 \mathrm{NE} 1 / 4 \mathrm{CH}$ ) e duas idades (jovem e superjovem), mantidos com dieta composta de silagem de milho e concentrado, com relação volumoso:concentrado de 50:50. As carcaças, após o abate, foram identificadas e resfriadas retirando-se um bife da porção do músculo Longissimus dorsi, que foi seco em estufa, moído, identificado e armazenado para extração dos lipídeos e determinação dos ácidos graxos, realizada em cromatógrafo a gás. Não houve interação significativa categoria $\times$ grupo genético para marmoreio, espessura de gordura e relação músculo:gordura, utilizados como co-variáveis. O total de ácidos graxos trans 18 nos animais superjovens foi maior $(2,46 \%)$ que nos jovens $(1,87 \%)$. A maioria dos ácidos graxos de cadeia curta $(75 \%)$ e de cadeia média $(91,7 \%)$ não foi influenciada pelo grupo genético. Os valores de ácido linoléico conjugado (CLA) não diferiram entre os grupos genéticos. Animais com predominância Nelore apresentaram maior grau de saturação nos ácidos graxos (média de 54,7\%) em comparação aos de predominância Charolês (média de 49,5\%). A relação de ácidos graxos insaturados/saturados nos animais Charolês foi maior que nos animais Nelore.

Palavras-chave: Charolês, CLA, gordura, Nelore, silagem

\section{Fatty acids profile in meat of steers from different ages and genetic groups finished in feedlot}

\begin{abstract}
For the conduction of this work, 24 males from four different genetic groups ( $5 / 8$ Charolais (CH) $3 / 8$ Nellore $(\mathrm{NE}) ; 5 / 8 \mathrm{NE} 3 / 8 \mathrm{CH} ; 3 / 4 \mathrm{CH} 1 / 4 \mathrm{NE} \mathrm{e} 3 / 4 \mathrm{NE} 1 / 4 \mathrm{CH}$ ) and two ages: steers and young steers were used. The animals received a diet composed of corn silage and concentrate with roughage:concentrate ratio of 50:50. After slaughter, the carcasses were identified and chilled. A steak from the longissimus muscle was collected and dried in stove, grounded, identified and stored for lipid extraction. The fatty acids (FA) determination was performed through gas chromatograph. No significant interaction was observed between category and genetic groups and marbling, fat thickness, muscle:fat ratio, used as co-variables. The total trans18 FA was higher $(2.46 \%)$ for young steers in relation to steers (1.87\%). Most short-chain (75\%) and medium-chain (91.7\%) FA were not influenced by the genetic group. CLA values did not differ between CH-NE crossbred animals. Animals with NE predominance showed higher saturated FA (average of 54.7\%) in relation to $\mathrm{CH}$ animals (average of $49.5 \%$ ). In relation to the unsaturated/saturated ratio, higher value was observed for $\mathrm{CH}$ animals.
\end{abstract}

Key Words: Charolais, CLA, fat, Nellore, silage

\section{Introdução}

A bovinocultura brasileira conquistou nos últimos anos importante espaço no mercado mundial de carnes. No entanto, cada vez mais é necessário investir na qualidade da carne para manutenção e expansão desse mercado. A redução da idade de abate e a escolha do grupo genético têm sido amplamente estudadas como fatores de melhora nas qualidades organolépticas da carne (Vaz et al., 2002; Pacheco et al., 2005; Menezes et al., 2005), porém, recentemente, a preocupação com a qualidade nutricional da carne vem ganhando força. A carne bovina, em especial, é considerada

Este artigo foi recebido em 4/6/2007 e aprovado em 11/8/2008.

Correspondências devem ser enviadaspara:patimetz@hotmail.com 
uma das carnes com maior efeito prejudicial à saúde humana, em razão de sua composição lipídica, constituída pelos ácidos graxo, principalmente os saturados e trans. Entretanto, tem sido amplamente demonstrado que ácidos graxos poliinsaturados de cadeia longa participam de vários processos metabólicos benéficos à saúde humana (Cook et al., 2001; Varela et al., 2004) e que as gorduras da carne de animais ruminantes são fontes naturais de alguns desses ácidos graxos, como os isômeros de ácido linoléico conjugado (CLA), em particular o cis-9, trans-11 (French et al., 2000).

As variações nas concentrações de ácidos graxos na carne de bovinos estão relacionadas à alimentação, à biohidrogenação ruminal, a métodos de análise e corte da carne e a influências genéticas (Mulvihill, 2001). Segundo Nürnberg et al. (1998), com o aumento da idade dos animais, os níveis de ácidos graxos saturados (SFA) aumentam e os de ácidos graxos poliinsaturados (PUFA) diminuem. Esses autores analisaram o perfil de ácidos graxos no tecido adiposo subcutâneo de vacas Hereford e Brahman e observaram maior porcentagem de ácidos graxos saturados e menor de poliinsaturados e monoinsaturados (MUFA) em vacas Hereford. Deschamps et al. (2004), estudando a influência do grau de sangue Charolês-Nelore em novilhos alimentados com silagem e concentrado, observaram que novilhos com $62,5 \%$ de sangue Nelore apresentaram menor valor de ácidos graxos saturados e maior valor de poliinsaturados em relação às demais combinações genéticas.

O objetivo neste trabalho foi avaliar a influência da idade e do grupo genético na composição de ácidos graxos da carne de novilhos terminados em confinamento.

\section{Material e Métodos}

O experimento foi realizado na fazenda experimental do Departamento de Zootecnia da Universidade Federal de Santa Maria, entre julho e dezembro de 2003. Do rebanho experimental, foram escolhidos ao acaso 24 bovinos machos castrados com 7 meses de idade, de quatro cruzamentos - Charolês $(\mathrm{CH}) \times$ Nelore $(\mathrm{NE})(5 / 8 \mathrm{CH}, 5 / 8 \mathrm{NE}, 3 / 4 \mathrm{CH}$ e $3 / 4 \mathrm{NE}$ ) - e duas idades (jovem e superjovem). Os animais jovens possuíam idade média inicial de 20 meses e foram abatidos aos 22 meses e os superjovens, idade média inicial de 8,1 meses e foram abatidos aos 13,1 meses de idade.

Antes do experimento, os animais foram adaptados durante 14 dias às instalações e à dieta experimental e submetidos ao controle de ecto e endoparasitas, com aplicação subcutânea de produto comercial à base de ivermectina, conforme recomendações do fabricante.
Durante o período experimental, os animais foram mantidos com dieta composta de silagem de milho e concentrado, fornecidos à vontade, duas vezes ao dia, uma pela manhã $(8 \mathrm{~h})$ e outra à tarde $(17 \mathrm{~h})$, em quantidade suficiente para ocorrer $10 \%$ de sobras. O concentrado era colocado sobre o volumoso no comedouro e misturado manualmente. A dieta foi calculada segundo o NRC (1996) objetivando ganho médio diário de peso de 1,30 kg/animal, com consumo de matéria seca de $2,5 \mathrm{~kg} / 100 \mathrm{~kg}$ de peso vivo. Para todos os animais, a dieta utilizada apresentou relação volumoso:concentrado de 50:50 e continha 16\% de proteína bruta (PB) para os animais superjovens e $13 \%$ para os jovens. O concentrado foi constituído de farelo de trigo, farelo de soja, milho em grão triturado, calcário calcítico, uréia, sal comum e ionóforo (monensina sódica).

Como o critério para abate dos animais foi o peso final, de $330 \mathrm{~kg}$, os animais superjovens foram mantidos em confinamento durante 73 dias, para ganho médio diário de $1,16 \mathrm{~kg}$, e os animais jovens, durante 155 dias, para ganho médio diário de $1,57 \mathrm{~kg}$. No entanto, o consumo diário de matéria seca foi de 8,37 kg para animais jovens e 7,07 kg para animais superjovens.

Amostras representativas dos componentes da dieta (Tabela 1) foram coletadas no início da adaptação e semanalmente durante o período experimental. As amostras foram pré-secas em estufa de ar forçado a $55^{\circ} \mathrm{C}$, durante 72 horas, para determinação do teor de matéria parcialmente seca e posteriormente foram trituradas em moinho tipo Willey com peneira com crivos de $1 \mathrm{~mm}$. Nestas amostras, foram determinados os teores de matéria seca, matéria mineral, proteína bruta, extrato etéreo (EE), fibra em detergente neutro (FDN), fibra em detergente ácido (FDA) e lignina. O teor de nitrogênio total $(\mathrm{N})$ foi determinado pelo método de Kjeldahl (método 984.13 AOAC, 1995), modificado, com uma solução de ácido bórico $(4 \% \mathrm{p} / \mathrm{v})$ como receptor da amônia livre durante a destilação, uma solução de $0,2 \%$ (p/v) de verde bromocresol e $0,1 \%(\mathrm{p} / \mathrm{v})$ de vermelho de metila como indicador e uma solução padrão de ácido sulfúrico para titulação. Os teores de fibra em detergente neutro (FDN) $\operatorname{com} \alpha$-amilase, de fibra em detergente ácido (FDA) e de lignina em detergente ácido (LDA) foram determinados de acordo com metodologia descrita por Robertson \& Van Soest (1981). O teor de gordura da amostra foi determinado em éter etílico em sistema de refluxo, a $180^{\circ} \mathrm{C}$ durante 2 horas, e de nitrogênio insolúvel em detergente neutro e ácido foram determinados de acordo com Licitra et al. (1996). Para obtenção do teor de nutrientes digestíveis totais (NDT), utilizou-se a equação proposta pelo NRC (2001). 
Tabela 1 - Composição química dos alimentos da dieta

\begin{tabular}{lcccc}
\hline Nutriente $(\%$ MS) & \multicolumn{2}{c}{ Componente da dieta } \\
\cline { 2 - 5 } & Farelo de trigo & Farelo de soja & Grão de milho & Silagem de milho \\
\hline Matéria seca & 88,08 & 88,81 & 87,81 & 32,35 \\
Proteína bruta & 14,98 & 50,52 & 8,77 & 5,93 \\
Extrato etéreo & 3,81 & 2,80 & 3,00 & 3,89 \\
Lignina & 3,38 & 1,89 & 0,45 & 5,79 \\
Matéria mineral & 6,04 & 6,14 & 1,88 & 5,56 \\
Fibra em detergente neutro & 46,07 & 21,73 & 17,12 & 58,96 \\
Fibra em detergente ácido & 13,63 & 6,91 & 12 & 34,05 \\
Nutrientes digestíveis totais & 76,75 & 85,00 & 88,26 & 68,82 \\
\hline
\end{tabular}

Os animais jovens e superjovens, por ocasião do abate, ficaram em jejum de sólidos e líquidos durante 14 horas e foram transportados a um frigorífico comercial. O abate ocorreu seguindo o fluxo normal do estabelecimento.

As carcaças dos animais foram identificadas e mantidas em refrigeração por 24 horas a $0^{\circ} \mathrm{C}$. Da meiacarcaça direita, retirou-se uma porção do músculo Longissimus, entre a 10 e $12^{\mathrm{a}}$ costelas, que foi identificada, envolta por uma lâmina de plástico e papel pardo e armazenada a $-18^{\circ} \mathrm{C}$. Após o congelamento da porção, retirou-se um bife que foi seco em estufa de ventilação forçada a $55^{\circ} \mathrm{C}$, moído com peneira de $1 \mathrm{~mm}$, identificado e armazenado para análise.

A extração dos lipídeos foi realizada utilizando-se o método de Folch et al. (1957), modificado. Em um tubo contendo 0,5 g de amostra, foi adicionado clorofórmio/ metanol (10 mL) na proporção de 2:1. Após 24 horas, foram adicionados $10 \mathrm{~mL}$ de água destilada e realizada a centrifugação a $500 \mathrm{xg}$ por 5 minutos para separação do conteúdo em fases. A fase orgânica (clorofórmio) foi transferida para tubos de ensaio com tampa e deixada em banho-maria a $40^{\circ} \mathrm{C}$, sob fluxo de ar comprimido, até restarem apenas lipídeos no fundo do tubo.

Foram adicionados ao tubo $500 \mathrm{~mL}$ de $\mathrm{KOH} 0,4 \mathrm{M} \mathrm{em}$ metanol deixando-se em banho-maria a $60^{\circ} \mathrm{C}$ por mais 2 horas. Após o resfriamento dos tubos em temperatura ambiente, adicionou-se $1,5 \mathrm{~mL}$ de $\mathrm{H}_{2} \mathrm{SO}_{4}(1 \mathrm{M})$ em metanol. Os tubos foram deixados novamente em banho-maria $\left(60^{\circ} \mathrm{C}\right.$ por 2 horas) e resfriados adicionando ao seu conteúdo $2 \mathrm{~mL}$ de n-hexano para recuperação dos derivados. Os ésteres metílicos de ácidos graxos foram mantidos a $-18^{\circ} \mathrm{C}$ até sua análise.
A determinação dos ácidos graxos foi realizada em cromatógrafo a gás com detector de ionização de chama (FID) e coluna capilar Supelco SP2340 (60 $\mathrm{m} \times 0,25 \mathrm{~mm} \times 0,2 \mu \mathrm{m})$. As temperaturas do detector e do injetor foram de 260 e $240^{\circ} \mathrm{C}$, respectivamente. A programação de aquecimento da coluna foi iniciada com $140^{\circ} \mathrm{C}$ por 5 minutos e aumento de $4^{\circ} \mathrm{C}$ por minuto até a temperatura final de $240^{\circ} \mathrm{C}$, que foi mantida por 5 minutos. O fluxo de gás de arraste (H2) foi de $17 \mathrm{~mL} /$ minuto e o volume de injeção, de $0,5 \mu \mathrm{L}$ com razão de split de 1:100. A identificação dos picos, assim como sua quantificação, foi feita por meio da comparação dos tempos de retenção e da área dos picos das amostras com as de padrões de ésteres metílicos de ácidos graxos (Supelco 37 components FAMEs Mix, ref. 47885-U).

Para obtenção das estimativas dos índices de $\Delta^{9}$-dessaturase, utilizaram-se as seguintes fórmulas:

$\mathrm{C} 16=100 *(\mathrm{C} 16: 1 \mathrm{n}-9 /(\mathrm{C} 16: 0+\mathrm{C} 16: 1 \mathrm{n} 9)) \mathrm{e}$

$\mathrm{C} 18=100 *(\mathrm{C} 18: 1 \mathrm{n}-9 /(\mathrm{C} 18: 0+\mathrm{C} 18: 1 \mathrm{n} 9))$

$\mathrm{O}$ delineamento experimental utilizado foi o inteiramente casualizado, em arranjo fatorial $4 \times 2$, composto de quatro quatro grupos genéticos e duas categorias. Cada tratamento foi composto de 12 repetições, de modo que cada unidade experimental foi constituída de um animal. A análise de variância foi realizada utilizando-se o marmoreio, a espessura de gordura e a relação músculo:gordura (kg de músculo/kg de gordura) como co-variáveis (Tabela 2), com a comparação de médias pelo teste t. A análise de contraste entre os grupos genéticos foi feita contrastando-se animais com predominância Charolês $\left(3 / 4 \mathrm{CH}^{1 / 4} \mathrm{NE} e\right.$ $5 / 8 \mathrm{CH} 3 / 8 \mathrm{NE})$ e animais com predominância Nelore $(3 / 4 \mathrm{NE}$ $1 / 4 \mathrm{CH}$ e $5 / 8 \mathrm{CH} 3 / 8 \mathrm{NE}$ ). As análises foram realizadas utilizando-se o pacote estatístico Statistical Analysis System (SAS, 1997). 
Tabela 2 - Quadrados médios das análises de variância das co-variáveis e teste F

\begin{tabular}{|c|c|c|c|c|c|c|c|c|}
\hline \multirow[t]{3}{*}{ Ácido graxo } & \multicolumn{2}{|c|}{ Grau de liberdade } & \multicolumn{4}{|c|}{ Quadrado médio } & \multirow{3}{*}{ Teste F } & \multirow{3}{*}{$\mathrm{R}^{2}$} \\
\hline & \multirow[t]{2}{*}{ Modelo } & \multirow[t]{2}{*}{ Erro } & \multicolumn{3}{|c|}{ Modelo } & \multirow[t]{2}{*}{ Erro } & & \\
\hline & & & $\begin{array}{l}\text { Espessura de } \\
\text { gordura subcutânea }\end{array}$ & Marmoreio & $\begin{array}{c}\text { Relação } \\
\text { músculo:gordura }\end{array}$ & & & \\
\hline $\mathrm{C} 4: 0$ & 7 & 24 & 0,77 & 0,35 & 0,70 & 0,5954 & 1,88 & 0,1177 \\
\hline C6:0 & 7 & 24 & 0,00001 & 0,00038 & 0,00001 & 0,0004 & 0,63 & 0,7243 \\
\hline C8:0 & 7 & 24 & 0,00028 & 0,00047 & 0,00041 & 0,0007 & 0,96 & 0,4782 \\
\hline C10:0 & 7 & 24 & 0,00178 & 0,00080 & 0,00006 & 0,0002 & 1,67 & 0,1639 \\
\hline C12:0 & 7 & 24 & 0,00029 & 0,00038 & 0,00002 & 0,0003 & 1,68 & 0,1622 \\
\hline C13:0iso & 7 & 24 & 0,00019 & 0,00032 & 0,00012 & 0,0005 & 0,80 & 0,5931 \\
\hline C13:0ant & 7 & 24 & 0,00026 & 0,00141 & 0,00368 & 0,0035 & 1,75 & 0,1442 \\
\hline C14:0 & 7 & 24 & 0,00379 & 0,14024 & 0,54251 & 0,2347 & 0,64 & 0,7200 \\
\hline C14:0iso & 7 & 24 & 0,00007 & 0,00005 & 0,00006 & 0,0003 & 0,79 & 0,6029 \\
\hline C14:1c9 & 7 & 24 & 0,02724 & 0,05535 & 0,28409 & 0,0402 & 1,30 & 0,2904 \\
\hline C15:0 & 7 & 24 & 0,00014 & 0,00037 & 0,00067 & 0,0021 & 0,83 & 0,5716 \\
\hline C15:0iso & 7 & 24 & 0,00027 & 0,00031 & 0,00000 & 0,0013 & 3,49 & 0,0102 \\
\hline C15:0ant & 7 & 24 & 0,00006 & 0,00176 & 0,00218 & 0,0009 & 2,10 & 0,0831 \\
\hline C16:0 & 7 & 24 & 0,012868 & 5,29135 & 10,0458 & 2,2693 & 1,06 & 0,4157 \\
\hline C16:0iso & 7 & 24 & 0,001252 & 0,00148 & 0,00146 & 0,0007 & 1,34 & 0,2744 \\
\hline C16:1c9 & 7 & 24 & 0,061109 & 0,50822 & 1,01443 & 0,2000 & 4,12 & 0,0042 \\
\hline C17:0 & 7 & 24 & 0,010253 & 0,00557 & 0,01361 & 0,0407 & 1,05 & 0,4222 \\
\hline C17:0iso & 7 & 24 & 0,011089 & 0,00040 & 0,00464 & 0,0056 & 2,13 & 0,0793 \\
\hline C17:1 & 7 & 24 & 0,004281 & 0,11404 & 0,01305 & 0,0506 & 0,50 & 0,8254 \\
\hline $\mathrm{C} 18: 0$ & 7 & 24 & 0,023262 & 16,3314 & 34,8639 & 3,9990 & 2,63 & 0,0364 \\
\hline C18:1t11 & 7 & 24 & 0,173971 & 0,01052 & 0,14046 & 0,0381 & 4,82 & 0,0017 \\
\hline $\mathrm{C} 18: 2 \mathrm{c} 9 \mathrm{t} 11$ & 7 & 24 & 0,007234 & 0,02509 & 0,06115 & 0,0094 & 3,04 & 0,0194 \\
\hline C18:3 & 7 & 24 & 0,001481 & 0,00004 & 0,00272 & 0,0006 & 2,80 & 0,0279 \\
\hline C20:0 & 7 & 24 & 0,001522 & 0,00148 & 0,00377 & 0,0020 & 0,89 & 0,5317 \\
\hline C20:3 & 7 & 24 & 0,000204 & 0,00002 & 0,00021 & 0,0002 & 1,47 & 0,2255 \\
\hline C20:4 & 7 & 24 & 0,000624 & 0,00164 & 0,01384 & 0,0043 & 1,60 & 0,1828 \\
\hline C20:5 & 7 & 24 & 0,000357 & 0,00225 & 0,00392 & 0,0077 & 0,93 & 0,5038 \\
\hline C22:0 & 7 & 24 & 0,000432 & 0,00004 & 0,00019 & 0,0001 & 2,12 & 0,0802 \\
\hline C22:1 & 7 & 24 & 0,000328 & 0,00160 & 0,00001 & 0,0052 & 1,64 & 0,1716 \\
\hline $\mathrm{C} 22: 2$ & 7 & 24 & 0,006418 & 0,00084 & 0,11430 & 0,0589 & 0,84 & 0,5655 \\
\hline $\mathrm{C} 22: 5$ & 7 & 24 & 0,000684 & 0,00031 & 0,00034 & 0,0003 & 1,42 & 0,2418 \\
\hline C22:6 & 7 & 24 & 0,000024 & 0,00011 & 0,00017 & 0,0008 & 1,97 & 0,1019 \\
\hline C24:0 & 7 & 24 & 0,001217 & 0,00034 & 0,00157 & 0,0013 & 1,37 & 0,2634 \\
\hline C24:1 & 7 & 24 & 0,000073 & 0,00107 & 0,00000 & 0,0010 & 0,90 & 0,5233 \\
\hline
\end{tabular}

\section{Resultados e Discussão}

Não houve interação significativa categoria $\times$ grupo genético para nenhum ácido graxo estudado, portanto, os efeitos foram tratados separadamente. Também não houve efeito $(\mathrm{P}>0,05)$ da idade dos animais (Tabela 3$)$ sobre a composição de ácidos graxos de cadeia curta, entre C4:0 e C10:0. O ácido graxo de cadeia curta com maior presença na carne, tanto dos animais superjovens quanto dos animais jovens, foi o ácido butírico (C4:0), que teve seu valor reduzido com o aumento da idade $(3,910$ para animais superjovens e 2,995 para animais jovens).

Os ácidos graxos de cadeia média, entre $\mathrm{C} 12$ e C16, em sua maioria ( $92 \%$ ), não sofreram modificação com a idade de abate. Não foram observadas alterações significativas $(\mathrm{P}>0,05)$ na porcentagem dos ácidos graxos mirístico
(C14:0), pentadecanóico (C15:0), palmítico (C16:0) e palmitoléico (C16:1). Entretanto, a composição em ácido graxo iso-pentadecanóico ( $\mathrm{C} 15: 0$ iso $)$ foi maior $(\mathrm{P}<0,05)$ nos animais abatidos com menor idade $(0,168 \%$ nos jovens e $0,203 \%$ nos superjovens).

Os ácidos graxos de cadeia média com maior participação percentual na carne de novilhos superjovens e jovens foram o mirístico (C14:0) e o palmítico (C16:0). Com o aumento da idade, houve acréscimo numérico no percentual destes ácidos graxos saturados de cadeia média. Hecker et al. (1975), no entanto, observaram decréscimo na composição dos ácidos graxos mirístico e C12:0 com o aumento da idade dos animais. Neste trabalho, a diminuição da idade não foi suficiente para ocasionar mudança ( $P>0,05)$ na composição dos ácidos graxos de cadeia curta e média. De acordo com Beorlegui (2004), os ácidos graxos de cadeia média (C12:0-C16:0) aumentam tanto a concen- 
Tabela 3 - Composição em ácidos graxos na carne de novilhos de duas categorias de abate

\begin{tabular}{|c|c|c|c|}
\hline \multirow[t]{2}{*}{ Ácido graxo (\%) } & \multicolumn{2}{|c|}{ Categoria } & \multirow[t]{2}{*}{ Probabilidade } \\
\hline & Superjovem & Jovem & \\
\hline \multicolumn{4}{|c|}{ Cadeias curta e média } \\
\hline $\mathrm{C} 4: 0$ & 3,910 & 2,995 & 0,3440 \\
\hline C6:0 & 0,001 & 0,003 & 0,7456 \\
\hline $\mathrm{C} 8: 0$ & 0,000 & 0,031 & 0,1678 \\
\hline C10:0 & 0,068 & 0,064 & 0,4300 \\
\hline C12:0 & 0,078 & 0,073 & 0,4589 \\
\hline C13:0iso & 0,017 & 0,000 & 0,4902 \\
\hline C13:0ant & 0,062 & 0,025 & 0,4588 \\
\hline C $14: 0$ & 2,670 & 3,036 & 0,2422 \\
\hline C14:0iso & 0,032 & 0,035 & 0,8523 \\
\hline $\mathrm{C} 14: 1 \mathrm{c} 9$ & 0,525 & 0,530 & 0,9544 \\
\hline C $15: 0$ & 0,298 & 0,318 & 0,4021 \\
\hline C15:0iso & 0,203 & 0,168 & 0,0141 \\
\hline C15:0ant & 0,207 & 0,174 & 0,0547 \\
\hline C16:0 & 24,443 & 26,404 & 0,1010 \\
\hline C16:0iso & 0,175 & 0,167 & 0,5400 \\
\hline C16:1c9 & 1,995 & 2,752 & 0,0644 \\
\hline \multicolumn{4}{|l|}{ Cadeia longa } \\
\hline C17:0 & 0,686 & 0,622 & 0,6145 \\
\hline C17:0iso & 0,436 & 0,334 & 0,0071 \\
\hline C $17: 1$ & 0,652 & 0,696 & 0,7868 \\
\hline C18:0 & 18,276 & 17,846 & 0,5437 \\
\hline C18:1t11 & 1,211 & 1,552 & 0,0431 \\
\hline $\mathrm{C} 18: 2 \mathrm{c} 9 \mathrm{t} 11$ & 0,242 & 0,265 & 0,4381 \\
\hline C18:3 & 0,399 & 0,343 & 0,4464 \\
\hline C20:0 & 0,136 & 0,079 & 0,0181 \\
\hline C20:1 & 0,044 & 0,093 & 0,0565 \\
\hline C20:3 & 0,037 & 0,030 & 0,3890 \\
\hline C20:4 & 0,219 & 0,151 & 0,3194 \\
\hline C20:5 & 0,096 & 0,020 & 0,4514 \\
\hline C22:0 & 0,000 & 0,019 & 0,0565 \\
\hline C22:1 & 0,004 & 0,011 & 0,7456 \\
\hline C22:2 & 0,642 & 0,523 & 0,5845 \\
\hline C22:5 & 0,031 & 0,013 & 0,1694 \\
\hline C22:6 & 0,046 & 0,029 & 0,4873 \\
\hline C24:0 & 0,070 & 0,091 & 0,2694 \\
\hline C24:1 & 0,003 & 0,008 & 0,7456 \\
\hline
\end{tabular}

tração de colesterol no plasma humano como a de lipoproteína de baixa densidade (LDL).

A diferença de aproximadamente 10 meses de idade dos animais não foi suficiente para ocasionar diferenças significativas na composição de ácidos graxos de cadeia longa, pois aproximadamente $90,3 \%$ desses ácidos graxos nas carnes dos animais foram semelhantes (Tabela 3). Contudo, observou-se diferença significativa na porcentagem dos ácidos graxos iso-heptadecanóico (C17:0iso; $\mathrm{P}=0,0071)$, vaccênico (C18:1trans $11 ; \mathrm{P}=0,0431)$ e ácido araquídico (C20:0; $\mathrm{P}=0,0181)$, que decresceu com o avançar da idade dos animais.

O ácido graxo vaccênico é formado pela biohidrogenização de um isômero posicional e geométrico derivado do ácido linoléico, chamado CLA (C18:2cis9-trans11 e
C18:2cis12-trans 10). Muitas vezes, a biohidrogenização do ácido graxo linoléico não chega a completar-se, assim, quantidades significativas de ácido graxo conjugado e de trans-monoinsaturados, como o ácido graxo vaccênico, alcançam o duodeno e são absorvidas, ficando no leite ou no tecido (Beorlegui, 2004).

O ácido linoléico conjugado (CLA) também pode ser formado endogenamente pela dessaturação do ácido graxo vaccênico por uma enzima presente na glândula mamária e no tecido adiposo, a $\Delta$-9-dessaturase (Medeiros, 2002). A $\Delta$-9-dessaturase também é encontrada em tecidos humanos, por isso, aumentos no consumo de ácido graxo vaccênico poderiam ter os mesmos efeitos benéficos associados à ingestão de CLA (Beorlegui, 2004). De acordo com Mulvihill (2001), em estudos animais, o CLA reduziu os riscos de tumores mamários e inibiu a indução de tumores de pele e, por ter propriedades antiteratogênicas, de imuno-mediação, aumenta a eficiência no crescimento, reduz a gordura corporal e previne a diabetes. Assim, a carne de animais superjovens, apesar de seu teor numericamente inferior de CLA (C18:2 c9t11) (0,242 vs 0,265\%), apresentou valores superiores $(\mathrm{P}<0,05)$ de ácido graxo vaccênico.

Não houve diferença $(P>0,05)$ no percentual total de ácidos graxos saturados e insaturados, resultado contraditório ao da literatura (Tabela 4). Segundo Nürnberg et al. (1998), a quantidade de tecido adiposo aumenta com a idade e ocasiona mudanças, como o rápido crescimento do diâmetro da célula do tecido adiposo até os 12 meses de idade. Após este período, ocorre pequena redução do crescimento até os 2 anos de idade. Com o tempo, a velocidade de crescimento dos adipócitos diminui, aumentando a importância relativa da gota lipídica em relação à membrana, onde se concentram os ácidos graxos insaturados (Medeiros, 2002). Assim, o perfil de ácidos graxos fica menos insaturado com o passar do tempo, pois os ácido graxo poliinsaturados estão relacionados à fração de fosfolipídios, que também reduzem como o passar do tempo (Duckett et al., 1993). Mesmo assim, neste trabalho, a diferença de idade dos animais provavelmente não foi suficiente para ocasionar mudanças, tanto em crescimento de adipócito quanto em deposição de gota lipídica, portanto, não interferiu no perfil de ácidos graxos.

A idade de abate não influenciou o total de ácidos graxos cis 18 . O total de trans $18(2,46 \%)$ na carne dos animais superjovens foi superior ao dos animais jovens $(1,873 ; \mathrm{P}=0,0412)$. Os ácidos graxos trans são insaturados e, ao contrário dos ácidos graxos insaturados cis, possuem na sua ligação dupla os hidrogênios dispostos de forma transversal e são resultado da biohidrogenação ruminal ou 
Tabela 4 - Composição dos ácidos graxos da carne de animais de duas categorias de abate

\begin{tabular}{|c|c|c|c|}
\hline \multirow[t]{2}{*}{ Ácido graxo (\%) } & \multicolumn{2}{|c|}{ Categoria } & \multirow[t]{2}{*}{ Probabilidade } \\
\hline & Superjovem & Jovem & \\
\hline Saturados ${ }^{1}$ & 51,761 & 52,489 & 0,3954 \\
\hline Insaturados ${ }^{2}$ & 48,421 & 47,579 & 0,3300 \\
\hline Monoinsaturados ${ }^{3}$ & 43,977 & 44,165 & 0,9020 \\
\hline Poliinsaturados ${ }^{4}$ & 4,412 & 3,379 & 0,3873 \\
\hline $\begin{array}{l}\text { Relação insaturados/ } \\
\text { Saturados }\end{array}$ & 0,945 & 0,905 & 0,2771 \\
\hline $\begin{array}{l}\text { Relação polinsaturados/ } \\
\text { saturados }\end{array}$ & 0,084 & 0,064 & 0,3619 \\
\hline Total cis $18^{5}$ & 38,501 & 38,383 & 0,9383 \\
\hline Total trans $18^{6}$ & 2,460 & 1,873 & 0,0412 \\
\hline $\begin{array}{l}\text { Ácidos graxos de } \\
\text { cadeia curta }\end{array}$ & 3,975 & 3,093 & 0,3664 \\
\hline $\begin{array}{l}\text { Ácidos graxos de } \\
\text { cadeia média }\end{array}$ & 30,705 & 33,680 & 0,1087 \\
\hline $\begin{array}{l}\text { Ácidos graxos de } \\
\text { cadeia longa }\end{array}$ & 65,470 & 63,259 & 0,1605 \\
\hline Índice $\Delta^{9}$-dessaturase $\mathrm{C} 16^{7}$ & 7,80 & 9,11 & 0,1504 \\
\hline Índice $\Delta^{9}$-dessaturase $\mathrm{C} 18^{8}$ & 67,01 & 67,16 & 0,9498 \\
\hline
\end{tabular}

${ }^{1}$ Saturados = C4:0; C6:0; C8:0; C10:0; C12:0; C13:0iso; C13:0ant; C14:0iso; C14:0; C15:0iso; C15:0ant; C14:1c9; C15:0; C16:0iso; C16:0; C17:0iso; C17:0; C18:0; C20:0; C22:0; C24:0.

${ }_{2}$ Insaturados = monoinsaturado+polinsaturado.

${ }^{3}$ Monoinsaturados = C16:1c9; C17:1; C18:1t6; C18:1t9; C18:1t10; C18:1t11; C18:1t12; C18:1c9; C18:1c11; C18:1c12; C18:1c13; C18:1t16; C18:1c15; C20:1; C22:1; C24:1.

${ }^{4}$ Poliinsaturados = C18:2t11c15; C18:2c9c12; C18:3; C18:2c9t11; C20:3; $\mathrm{C} 20: 4$; C22:2; C20:5; C22:5; C22:6.

${ }^{5} \mathrm{AG}$ Cis $18=\mathrm{C} 18: 1 \mathrm{c} 9 ; \mathrm{C} 18: 1 \mathrm{c} 11 ; \mathrm{C} 18: 1 \mathrm{c} 12 ; \mathrm{C} 18: 1 \mathrm{c} 13 ; \mathrm{C} 18: 1 \mathrm{c} 15$; C18:2t11c15; C18:2c9c12;

${ }^{6}$ AG Trans18= C18:1t9, C18:1t10; C18:1t11; C18:1t12; C18:1t16; C18:1t18; C18:2t11c15; C18:2c9c12;

7 Ïndice $\mathrm{D}^{9}$-dessaturase C16 $100 *(\mathrm{C} 16: 1 n-9 /(\mathrm{C} 16: 0+\mathrm{C} 16: 1 n 9))$

${ }^{8}$ Ïndice $\mathrm{D}^{9}$-dessaturase $\mathrm{C} 18=100 *(\mathrm{C} 18: 1 n-9 /(\mathrm{C} 18: 0+\mathrm{C} 18: 1 n 9))$

de processos industriais. O conceito geral de ácidos graxos trans traduz-se em efeitos prejudiciais à saúde humana, Sanhueza et al. (2002) relacionaram esses efeitos aos lipídios sanguíneos, à ação inibitória de enzimas hepáticas, à modificação da fluidez das membranas celulares e ao potencial arteriogênico. De acordo com Chiara et al. (2002), os ácidos graxos trans estão relacionados ao aumento de doenças coronárias e seu principal efeito metabólico seria sua ação hipercolesterolêmica, que eleva o colesterol total e a lipoproteína de baixa densidade (LDL-c), reduzindo a lipoproteína de alta densidade (HDL-c) e resultando em significativo aumento da relação LDL-c/HDL-c. Essa relação é considerada o prognóstico mais importante para as doenças cardiovasculares, em razão dos níveis plasmáticos de lipídios (Chiara et al., 2002).

O total de ácidos graxos de cadeias curta, média ou longa não sofreu nenhum efeito da idade de abate dos animais.

A $\Delta^{9}$-dessaturase é a enzima responsável pela retirada de moléculas de hidrogênio das cadeias carbonadas dos ácidos graxos saturados, transformando-os em ácidos graxos insaturados. Essa enzima está presente tanto na glândula mamária quanto no tecido adiposo e sua atividade promove a formação endógena de CLA de ácidos graxos monoinsaturados, como C16:1 e C18:1 (Medeiros, 2002). Neste estudo, a categoria animal não influenciou a atividade da $\Delta^{9}$-dessaturase.

Laborde et al. (2001) citam que a recomendação Canadense para o consumo diário para humanos inclui o máximo de $11 \mathrm{~g}$ de ácidos graxos saturados e mínimo de 3,8 mg do total de ácidos graxos poliinsaturados, em $1.000 \mathrm{kcal}$ de energia consumida. Em comparação aos dados compilados por Laborde et al. (2001), neste trabalho, em $100 \mathrm{~g}$ de carne de animais superjovens, obtiveram-se 51,8 g de ácidos graxos saturados, enquanto, na carne dos animais jovens, esse valor foi de 52,5 $\mathrm{g}$.

Mulvihill (2001) comparou o teor de C18:2c9,t11 na carne de animais criados em países como Austrália (7,6 mg/g de gordura) e Estados Unidos (1,7-2,7 mg/g de gordura) e atribuiu essa diferença à alimentação dos animais, uma vez que animais australianos são basicamente criados em pastagem, enquanto os americanos são alimentados com altas quantidades de grãos na dieta. Os novilhos jovens utilizados neste estudo apresentaram na carne $2,65 \mathrm{mg} / \mathrm{g}$ de CLA, enquanto nos superjovens esse valor foi de $2,42 \mathrm{mg} / \mathrm{g}$. Os valores encontrados neste estudo foram intermediários aos obtidos nos dois países e indicam que o nível de concentrado utilizado no confinamento interferiu na quantidade de CLA da carne.

A maioria $(75 \%)$ dos ácidos graxos de cadeia curta (C4:0-C10:0) não foi influenciada pelo grupo genético dos novilhos. No entanto, animais $3 / 4$ Nelore ( $75 \%$ de sangue NE) apresentaram valor superior $(\mathrm{P}<0,05)$ de ácido cáprico (C10:0) em relação aos demais grupos genéticos, indicando que o maior grau de sangue Nelore aumentou a proporção deste ácido graxo na carne de novilhos.

Os ácidos graxos de cadeia média, em sua maioria $(91,7 \%)$, também não foram influenciados pelo grupo genético. Entretanto, aqueles com maior proporção de sangue Nelore (3/4 Nelore) apresentaram maior valor percentual de ácido láurico (C12:0) $(0,122 \%)$, seguido dos animais $3 / 8$ Nelore $(62,5 \%$ de sangue Nelore) $(0,082 \%)$, que diferiram daqueles com maior grau de sangue Charolês ( $5 / 8$ e $3 / 4$ Charolês com 0,053 e 0,047\%, respectivamente).

Aproximadamente $96,8 \%$ dos ácidos graxos de cadeia longa não diferiram significativamente $(\mathrm{P}>0,05)$ entre os grupos genéticos estudados (Tabela 5). Houve maior acúmulo percentual de C18:0 (esteárico) nos animais 3/4 Ne e $3 / 8 \mathrm{NE}(20 \%$ e $19 \%$, respectivamente) em relação aos $5 / 8$ Charolês (15\%), enquanto os do grupo genético 
3/4 Charolês permaneceram com valores intermediários (17\%). Desta forma, houve acúmulo de ácido esteárico na carne de novilhos com o aumento do grau de sangue Nelore, fato relacionado à possível diferença de biohidrogenação ruminal, que poderia ser maior nas raças Bos taurus indicus, visto que não houve diferença significativa para a atividade de $\Delta^{9}$-dessaturase na conversão de C18:0 para C18:1 (Tabela6). Segundo Simoloupos (1991), o ácido graxo esteárico está relacionado a efeitos adversos à saúde humana por ser potencialmente trombogênico. Laborde et al. (2001), avaliando diferenças entre animais de maturidade precoce e tardia, observaram tendência $(\mathrm{P}=0,064)$ de animais Simental possuírem menor quantidade de C18:0 em relação aos Red Angus. Os valores encontrados neste estudo para C18:0 foram inferiores (média de 18\%) aos descritos em estudos realizados por Laborde et al. (2001) e
Malau-Aduli et al. (2000). Esses autores encontraram valores médios de 10,33\% para animais da raça Simental e 9,86\% para animais Red Angus (Laborde et al., 2001) e 11,2\% para animais Jersey e 11,9\% para animais Limousin (MalauAduli et al., 2000).

Muitos isômeros posicionais $(7,9 ; 8,10 ; 9,11 ; 10,12 \mathrm{ou}$ 11,13) e geométricos (cis [c],c; c,trans [t]; t,t ou t,c) do CLA são conhecidos, porém, o ácido rumênico (C18:2c9t11) é predominante e totaliza pelo menos $60 \%$ do total de CLA na carne (Mulvihill, 2001). Durante as análises de ácidos graxos da carne dos novilhos, observou-se a presença de CLA (C18:2c9t11), porém os valores percentuais deste ácidos graxos não diferiram entre os grupos genéticos. A análise de contraste comprovou que novilhos com maior grau de sangue Charolês apresentaram média de $0,272 \%$ e novilhos com maior grau de sangue Nelore apresentaram valor médio

Tabela 5 - Composição em ácidos graxos da carne de novilhos de quatro grupos genéticos

\begin{tabular}{|c|c|c|c|c|c|}
\hline \multirow[t]{2}{*}{ Ácido graxo } & \multicolumn{4}{|c|}{ Grupo genético } & \multirow[t]{2}{*}{ Probabilidade } \\
\hline & 3/4 Charolês & $3 / 4$ Nelore & $5 / 8$ Charolês & $5 / 8$ Nelore & \\
\hline \multicolumn{6}{|c|}{ Cadeias curta e média } \\
\hline $\mathrm{C} 4: 0$ & 2,590 & 4,132 & 3,050 & 4,039 & 0,6726 \\
\hline C6:0 & 0,004 & 0,003 & 0,000 & 0,001 & 0,9369 \\
\hline C8:0 & 0,000 & 0,003 & 0,041 & 0,027 & 0,3257 \\
\hline C10:0 & $0,049 \mathrm{~b}$ & $0,086 \mathrm{a}$ & $0,063 b$ & $0,066 \mathrm{~b}$ & 0,0206 \\
\hline C $12: 0$ & 0,047 & 0,122 & 0,053 & 0,082 & 0,0051 \\
\hline C13:0iso & 0,007 & 0,000 & 0,042 & 0,000 & 0,5984 \\
\hline C13:0ant & 0,000 & 0,008 & 0,149 & 0,020 & 0,2223 \\
\hline C14:0 & 2,505 & 3,183 & 2,728 & 2,997 & 0,5135 \\
\hline C14:0iso & 0,034 & 0,033 & 0,037 & 0,028 & 0,9792 \\
\hline C14:1c9 & 0,535 & 0,441 & 0,701 & 0,432 & 0,3170 \\
\hline C15:0 & 0,285 & 0,321 & 0,279 & 0,345 & 0,2829 \\
\hline C15:0iso & 0,164 & 0,180 & 0,203 & 0,195 & 0,0925 \\
\hline C15:0ant & 0,166 & 0,197 & 0,175 & 0,223 & 0,1200 \\
\hline C16:0 & 24,859 & 25,277 & 25,071 & 25,586 & 0,8500 \\
\hline C16:0iso & 0,174 & 0,163 & 0,152 & 0,195 & 0,1371 \\
\hline $\mathrm{C} 16: 1 \mathrm{c} 9$ & 2,524 & 2,046 & 2,716 & 2,208 & 0,5998 \\
\hline \multicolumn{6}{|l|}{ Cadeia longa } \\
\hline C17:0 & 0,620 & 0,635 & 0,665 & 0,707 & 0,9277 \\
\hline C17:0iso & 0,370 & 0,364 & 0,394 & 0,412 & 0,3565 \\
\hline C $17: 1$ & 0,699 & 0,570 & 0,765 & 0,662 & 0,8826 \\
\hline C18:0 & $17,581 \mathrm{ab}$ & $20,034 \mathrm{a}$ & $15,176 b$ & $19,453 \mathrm{a}$ & 0,0338 \\
\hline $\mathrm{C} 18: 2 \mathrm{c} 9 \mathrm{t} 11$ & 0,224 & 0,227 & 0,320 & 0,242 & 0,1907 \\
\hline $\mathrm{C} 18: 3$ & 0,233 & 0,515 & 0,277 & 0,457 & 0,1689 \\
\hline C20:0 & 0,110 & 0,099 & 0,136 & 0,087 & 0,2912 \\
\hline C20:1 & 0,055 & 0,084 & 0,041 & 0,094 & 0,3543 \\
\hline C20:3 & 0,027 & 0,042 & 0,025 & 0,040 & 0,5302 \\
\hline C20:4 & 0,161 & 0,200 & 0,103 & 0,276 & 0,3502 \\
\hline C20:5 & 0,034 & 0,000 & 0,186 & 0,028 & 0,5711 \\
\hline C22:0 & 0,000 & 0,012 & 0,007 & 0,014 & 0,6566 \\
\hline C22:1 & 0,015 & 0,012 & 0,000 & 0,003 & 0,9369 \\
\hline C22:2 & 0,563 & 0,609 & 0,334 & 0,823 & 0,4731 \\
\hline $\mathrm{C} 22: 5$ & 0,026 & 0,041 & 0,000 & 0,027 & 0,1632 \\
\hline C22:6 & 0,028 & 0,018 & 0,064 & 0,040 & 0,6055 \\
\hline C24:0 & 0,072 & 0,092 & 0,065 & 0,090 & 0,7430 \\
\hline C24:1 & 0,011 & 0,009 & 0,000 & 0,003 & 0,9369 \\
\hline
\end{tabular}

${ }^{\mathrm{a}, \mathrm{b}}$ Letras diferentes na linha diferem entre si $(\mathrm{P}<0,05)$. 
Tabela 6 - Composição dos ácidos graxos da carne de novilhos de quatro grupos genéticos

\begin{tabular}{|c|c|c|c|c|c|}
\hline \multirow[t]{2}{*}{ Ácido graxo } & \multicolumn{4}{|c|}{ Grupo genético } & \multirow[t]{2}{*}{ Probabilidade } \\
\hline & 3/4 Charolês & $3 / 4$ Nelore & $5 / 8$ Charolês & $5 / 8$ Nelore & \\
\hline Saturados ${ }^{1}$ & $49,616 b$ & $54,936 \mathrm{a}$ & $49,387 b$ & $54,562 \mathrm{a}$ & 0,0220 \\
\hline Insaturados ${ }^{2}$ & $50,556 a$ & $45,036 b$ & $50,607 \mathrm{a}$ & $45,801 b$ & 0,0230 \\
\hline Monoinsaturados ${ }^{3}$ & 47,060 & 41,151 & 47,529 & 40,544 & 0,0807 \\
\hline Poliinsaturados 4 & 3,641 & 3,852 & 3,041 & 5,228 & 0,5361 \\
\hline Relação insaturados/saturados & $1.028 \mathrm{a}$ & $0,820 \mathrm{~b}$ & $1.018 \mathrm{a}$ & $0,835 b$ & 0,0326 \\
\hline Relação poliinsaturados/saturados & 0,069 & 0,069 & 0,063 & 0,096 & 0,5928 \\
\hline Total $\operatorname{cis} 18^{5}$ & 41,382 & 36,002 & 41,425 & 34,959 & 0,0971 \\
\hline Total trans $18^{6}$ & 2,016 & 2,177 & 2,080 & 2,394 & 0,6066 \\
\hline Cadeia curta & 2,627 & 4,224 & 3,154 & 4,132 & 0,6631 \\
\hline Cadeia média & 31,297 & 31,961 & 33,207 & 32,306 & 0,8220 \\
\hline Cadeia longa & 66,215 & 63,753 & 63,596 & 63,895 & 0,5176 \\
\hline Ïndice $\Delta^{9}$-dessaturase $\mathrm{C} 16^{7}$ & 9,28 & 8,33 & 8,68 & 7,53 & 0,5383 \\
\hline Ïndice $\Delta^{9}$-dessaturase $\mathrm{C} 18^{8}$ & 68,66 & 67,40 & 67,70 & 64,58 & 0,6564 \\
\hline 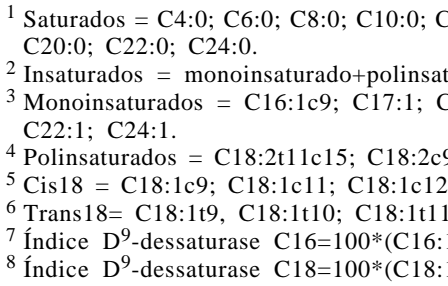 & $\begin{array}{l}\text { 2:0; C13:0iso; } \\
\text { Irado. } \\
\text { 18:1t6; C18:1t9; } \\
\text { 12; C18:3; C18 } \\
\text { C18:1c13; C18 } \\
\text { C18:1t12; C18 } \\
n-9 /(\mathrm{C} 16: 0+\mathrm{C} 16 \\
n-9 /(\mathrm{C} 18: 0+\mathrm{C} 18\end{array}$ & $\begin{array}{l}\text { 4:0iso; C14:0 } \\
\text { C18:1t11; C1 } \\
0: 3 ; \mathrm{C} 20: 4 ; \mathrm{C} \\
\mathrm{t} 11 \mathrm{c} 15 ; \mathrm{C} 18: \\
\text { t18; C18:2t1 }\end{array}$ & $\begin{array}{l}\text { 15:0ant; C14:1c) } \\
\text { c9; C18:1c11; } \\
\text { C22:5; C22:6. } \\
9 \text { c12; }\end{array}$ & $\begin{array}{l}\text { 6:0iso; C16:0 } \\
\text { 18:1c13; C18 }\end{array}$ & $\begin{array}{l}\text { iso; C17:0; C18:0 } \\
\text { C18:1c15; C20:1 }\end{array}$ \\
\hline
\end{tabular}

de $0,234 \%$ de CLA $(P=0,2670)$. Similarmente a este trabalho, Laborde et al. (2001), Mir et al. (2000) e Mir et al. (2002) não encontraram diferença nos valores de CLA na carne entre grupos genéticos de bovinos.

O total de ácidos graxos saturados e o de ácidos graxos insaturados diferiram $(\mathrm{P}<0,05)$ entre os grupos genéticos. $\mathrm{Na}$ análise de contraste, animais com predominância Nelore $\left(3 / 4 \mathrm{e}^{5 / 8 \mathrm{NE})}\right.$ apresentaram maior grau de saturação dos ácidos graxos $(54,75 \%)$ em comparação aos de predominância Charolês (média de 49,50\%), enquanto valores inversos foram observados para o grau de insaturação dos ácidos graxos, que foi maior nos novilhos com predominância Charolês $(50,58 \%)$ e menor para novilhos com predominância Nelore (média de 45,42\%).

A relação de ácidos graxos insaturados/saturados foi maior nos animais com predominância Charolês em relação aos Nelore, o que está relacionado à influência da precocidade em deposição de gordura dos animais Nelore em relação aos Charolês, visto que animais precoces em deposição estariam, a uma mesma idade, depositando gota lipídica, que é composta de ácidos graxos com maior saturação em relação aos menos precoces, que teriam relação gota lipídica:fosfolipídeos de membrana menor. Esses resultados confirmam os encontrados por Rule et al. (1997) e Laborde et al. (2001) e diferem dos reportados por Huerta-Leidnenz et al. (1993). Desta forma, é necessário estudar melhor as interações genéticas sobre o conteúdo de lipídios na carne de bovinos.
A atividade da enzima $\Delta^{9}$-dessaturase não diferiu entre os grupos genéticos estudados para a conversão de C16:0 e C18:0 em C16:1 e C18:1. Laborde et al. (2001), no entanto, avaliando animais Simental e Red Angus, observaram que animais Simental apresentaram $30 \%$ a mais de atividade de $\Delta^{9}$-dessaturase no C16:0 em relação aos Red Angus, porém esses autores não observaram diferença significativa na atividade de $\Delta^{9}$-dessaturase no C18:0.

De acordo com Chin et al. (1992), a carne de ovelha possui 5,6 $\mathrm{mg}$ de CLA por g, enquanto a bovina possui 2,9-4,3 mg/g e a de monogástricos apresenta valores inferiores (a de aves tem $0,9 \mathrm{mg} / \mathrm{g}$ e a de suínos, $0,6 \mathrm{mg} / \mathrm{g}$ ). Animais com predominância Charolês apresentaram média de 2,72 mg de CLA/g de carne e animais com predominância Nelore, média de $2,34 \mathrm{mg} / \mathrm{g}$, valores inferiores aos descritos por Chin et al. (1992).

\section{Conclusões}

A diminuição da idade de abate de bovinos de 24 para 14 meses de idade não influencia o perfil de ácidos graxos da carne. A carne de animais com maior participação de sangue Charolês possui perfil de ácidos graxos menos insaturado que a de animais com predominância de sangue Nelore.

\section{Literatura Citada}

BEORLEGUI, C.B. Cambios en el perfil de ácido grasos en productos animales en relación con la alimentación animal y humana. 
Importancia del ácido linoleico conjugado. 1. Rumiantes. In: CURSO DE ESPECIALIZACION FEDNA, 20., 2004, Barcelona. Anais... Barcelona: Fundación Española para el Desarrollo de la Nutrición Animal, 2004. p.79.

CHIARA, V.L.; SILVA, R.; JORGE, R. et al. Ácidos graxos trans: doenças cardiovasculres e saúde materno-infantil. Revista de Nutrição, v.15, n.3, p.341-349, 2002.

CHIN, S.F.; LIU, W.; STORKSON, J.M. et al. Dietary source of conjugated dienoic isomers of linoleic acid, newly recognized class of anticarcinogens. Journal of Food Composition and Analysis, v.5, p.185-197, 1992.

COOK, M.E.; WHIGHAM, L.D.; YANG, M. et al. CLA inhibits the induction of prostaglandin and leukotriene synthesis. A natural substitute for non-steroidal andti-inflammatory drugs. In INTERNATIONAL CONFERENCE ON CLA, 1., 2001, Alesund. Proceedings... Alesund: NATURAL ASA, 2001. p.6-7.

DESCHAMPS, C.F.; FIAMONCINI, J.; KOZLOSKI, G.V. et al. Avaliação do perfil de ácidos graxos de cadeia longa na carcaça de novilhos de diferentes graus de sangue Charolês:Nelore. In: REUNIÃO ANUAL DA SOCIEDADE BRASILEIRA DE ZOOTECNIA, 41., 2004, Campo Grande. Anais... Campo Grande: Sociedade Brasileira de Zootecnia, 2004. (CD-ROM).

DUCKETT, SK.; WAGNER, D.G.; YATES, L.D. et al. Effects of time on feed on beef nutrient composition. Journal of Animal Science, v.71, p.2079-2088, 1993.

FOLCH, J.; LEES, M.; SLOANE STANLEY, G.H. A simple method for the isolation and purification of total lipids from animal tissues. Journal of Biological Chemistry, v.226, p.497-509, 1957.

FRENCH, P.; STANTON, C.; LAWLESS, F. et al. Fatty acid composition, including conjugated linoleic acid of intramuscular fat from steers offered grazed grass, grass silage or concentrated-based diet. Journal of Animal Science, v.78, p.2849-2855, 2000 .

HECKER, A.L.; CRAMER, D.A.; HOUGHAM, D.F. Compositional and metabolic growth effects in the bovine muscle, subcutaneous and serum total fatty acids. Journal of Animal Science, v.40, p.144, 1975.

HUERTA-LEIDENZ, N.O.; CROSS, H.R.; SAVELL, J.W. et al. Comparison of the fatty acid composition of subcutaneous adipose tissue from mature Brahman and Hereford cows. Journal of Animal Science, v.71, p.625-630, 1993.

LABORDE, F.L.; MANDELL, I.B.;TOSH, J.J. et al. Breeds effect on growth performance, carcass characteristics, fatty acid composition, and palatability attributes in finishing steers. Journal of Animal Science, v.79, p.355-365, 2001.

LICITRA, G.; HERNANDEZ, T.M.; Van SOEST, P.J. Standartization of procedures for nitrogen fractionation of ruminant feeds. Animal Feed Science Technology, v.57, p.347-358, 1996.

MALAU-ADULI, A.E.O.; SIEBERT, B.D.; BOTTEMA, C.D.K. et al. Heterosis, sex and breed differences in the fatty acid composition of muscle phospholipids in beef cattle. Journal of Animal Physiology and Animal Nutrition, v.83, p.113$120,2000$.

MEDEIROS, S.R. Ácido linoléico conjugado: teores nos alimentos e seu uso no aumento da produção de leite com maior teor de proteína e perfil de ácidos graxos modificado. 2002. 114f. Dissertação (Mestrado em Agronomia) - Escola Superior de Agricultura Luiz de Queiroz, Piracicaba, 2002.
MENEZES, L.F.G.; RESTLE, J.; VAZ, F.N. et al. Composição física da carcaça e qualidade da carne de novilhos de gerações avançadas do cruzamento alternado entre as raças Charolês e Nelore, terminados em confinamento. Revista Brasileira de Zootecnia, v.34, n.3, p.946-956, 2005.

MIR, Z.; PATERSON, L.J.; MIR, P.S. Fatty acid composition and conjugated linoleic acid content of intramuscular fat in crossbred cattle with and without Wagyu genetics fed a barleybased diet. Canadian Journal of Animal Science, v. 80 , p.195-197, 2000.

MIR, P.S.; KUBER,P.S.; GASKINS, C.T. et al. Growth, carcass characteristics, muscle conjugated linoleic acid (CLA) content, and response to intravenous glucose challenge in high percentage Wagyu, Wagyu x Limousin, and Limousin steers fed sunflower oil-containing diets. Journal of Animal Science, v.80, p.2996-3004, 2002.

MULVIHILL, B. ruminant meat as a source of conjugated linoleic acid (CLA). British Nutrition Foundation Nutrition Bulletin, v.26, p.295-299, 2001,

NATIONAL RESEARCH COUNCI - NRC. Nutrient requirements of domestic animal. 7.rev.ed. Washington, D.C.: National Academy Press, 1996. 242p.

NATIONAL RESEARCH COUNCIL - NRC. Nutrient requirements of domestic animal. 7.rev.ed. Washington, D.C.: National Academy Press, 2001. 242p.

NÜRNBERG, K.; WEGNER, J.; ENDER, K. Factors influencing fat composition in muscle and adipose tissue of farm animals. Livestock Production Science, v.56, p.145-156, 1998.

PACHECO, P.S.; RESTLE, J.; SILVA, J.H. et al. Composição física da carcaça e qualidade da carne de novilhos jovens e superjovens de diferentes grupos genéticos. Revista Brasileira de Zootecnia, v.34, n.5, p.1691-1703, 2005.

ROBERTSON, J.B.; Van SOEST, P.J. The detergent system of analysis. In: JAMES, W.P.T.; THEANDER, O. (Eds.) The analysis of dietary fibre in food. New York: Marcel Dekker, 1981. p.123-158.

RULE, D.C.; MACNEIL, M.D.; SHORT, R.E. Influence of sire growth potential, time on feed, and growing-finishing strategy on cholesterol and fatty acids the growth carcass and Longissimus muscle of beef steers. Journal of Animal Science, v.75, p.1525-1533, 1997.

SANHUEZA, J.; NIETO, S.; VALENZUELA, A. acido linoleico conjugado: Un acido graso con isomeria trans potencialmente beneficioso. Revista Chilena de Nutrición, v.29, n.2, 2002, p. $98-105$.

STATISTICAL ANALYSIS SYSTEM - SAS. SAS/STAT user's guide: statistics. 8.ed. Version 6.11, Cary: 1997. v.6, 943p.

SIMOLOUPUS, A.P. Omega-3 fatty acids in health and disease and in growth and development. American Journal of Clinical Nutrition, v.54, p.438-463, 1991.

VARELA, A.; OLIETE, B.; MORENO, T. et al. Effect of pasture finishing on the meat characteristics and intramuscular fatty acid profile of steers of the Rubia Gallega breed. Meat Science, v.67, p.515-522, 2004.

VAZ, F.N.; RESTLE, J.; PACHECO, P.S. et al. Características da carcaça e da carne de novilhos superprecoces de três grupos genéticos, gerados por fêmeas de dois anos. Revista Brasileira de Zootecnia, v.31, n.5, p.1973-1982, 2002. 